\title{
Disability After Deployment Injury: Are Women and Men Service Members Different?
}

\author{
Jessica C. Rivera MD, Christina M. Hylden MD, \\ Anthony E. Johnson MD
}

Published online: 10 February 2015

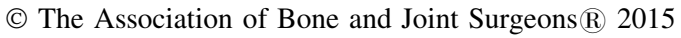

\begin{abstract}
Background Civilian trauma literature suggests sexual dimorphism in outcomes after trauma. Because women represent an increasing demographic among veterans, the question remains if war trauma outcomes, like civilian trauma outcomes, differ between genders.

Questions/purposes (1) Do women service members develop different conditions resulting in long-term disability compared with men service members after injuries sustained during deployment? (2) Do women service members have more or less severe disability after deployment injury compared with men service members? (3) Are men or women more likely to return to duty after combat injury?
\end{abstract}

Each author certifies that he or she, or a member of his or her immediate family, has no funding or commercial associations (eg, consultancies, stock ownership, equity interest, patent/licensing arrangements, etc) that might pose a conflict of interest in connection with the submitted article.

All ICMJE Conflict of Interest Forms for authors and Clinical Orthopaedics and Related Research ${ }^{\circledR}$ editors and board members are on file with the publication and can be viewed on request.

Each author certifies that his or her institution approved the human protocol for this investigation and that all investigations were conducted in conformity with ethical principles of research.

The opinions or assertions herein are the views of the authors and are not be construed as representative of the Department of Defense or the Department of the Army.

J. C. Rivera ( $\square)$

US Army Institute of Surgical Research, JBSA Fort Sam

Houston, TX, USA

e-mail: Jessica.c.rivera14.mil@mail.mil;

jessica.cross@us.army.mil

J. C. Rivera, C. M. Hylden, A. E. Johnson

San Antonio Military Medical Center, 3551 Roger Brooke Drive,

JBSA Fort Sam Houston, TX 78234, USA
Methods The Department of Defense Trauma Registry was queried for women injured during deployment from 2001 to 2011. The subjects were then queried in the Physical Evaluation Board database to determine each subject's return-to-duty status and what disabling conditions and disability percentages were assigned to those who did not return to duty. Frequency of disabling conditions, disability percentages, and return-to-duty rates for 368 women were compared with a previously published cohort of 450 men service members, 378 of whom had orthopaedic injuries.

Results Women who were unable to return to duty had a higher frequency of arthritic conditions (58\% [48 of 83] of women versus $35 \%$ [133 of 378] of men, $p=0.002$; relative risk $[\mathrm{RR}], 1.64 ; 95 \%$ confidence interval $[\mathrm{CI}]$, 1.307-2.067) and lower frequencies of general chronic pain ( $1 \%$ [one of 83] of women versus 19\% [59 of 378] of men, $\mathrm{p}<0.001$; RR, 0.08; 95\% CI, 0.011-0.549) and neurogenic pain disorders (1\% [one of 83] of women versus $7 \%$ [27 of 378] of men, $\mathrm{p}=0.0410$; RR, 0.169; 95\% CI, $0.023-1.224)$. Women had more severely rated posttraumatic stress disorder (PTSD) compared with men $(38 \% \pm 23 \%$ versus $19 \% \pm 17 \%)$. Forty-eight percent (64 of 133) of battle-injured women were unable to return to active duty, resulting in a lower return-to-duty rate compared with men (34\% [450 of 1333]; $\mathrm{p}=0.003)$.

Conclusions After deployment-related injury, women have higher rates of arthritis, lower rates of pain disorders, and more severely rated PTSD compared with men. Women are unable to return to duty more often than men injured in combat. These results suggest some difference between men's and women's outcomes after deployment injury, important information for military and Veterans Administration providers seeking to minimize postdeployment disability. 
Level of Evidence Level III, prognostic study.

\section{Introduction}

Traumatic injury is a leading cause of disability in the United States, resulting in millions of dollars of healthcare expenditures, days of work lost, and disability-adjusted life-years [4]; musculoskeletal conditions are among the most common posttraumatic disabilities [8]. Studies of civilians who have experienced traumatic injury suggest that men patients experience a higher case fatality rate but women experience a greater risk of complications despite their survival advantage [15, 35]. Return-to-civilian-work rates after a work-related injury are lower, and total days lost of work are higher for women compared with men [9, 28]. Among civilians who have experienced severe trauma, there appear to be important gender-related differences in terms of survival, return to work, and lingering disability.

Women veterans who have served in recent US contingency operations in Iraq (Operation Iraqi Freedom/ Operation New Dawn [OIF/OND], 2003-2011) and Afghanistan (Operation Enduring Freedom [OEF], 20012013) comprise a rapidly growing population seeking care within the Veterans Affairs (VA) healthcare system [1]. Evidence from the VA suggests that women veterans seeking care at the VA display different resource use compared with men veterans, including higher rates of primary care and mental health services $[12,21]$. The lead causes for medical evacuation for deployed females are mental health disorders [25, 26]. However, how military injury affects the genders differently is not clear and extrapolation from the civilian literature may not be externally valid given the types of injuries experienced in a deployed environment. Given the observed differences between men and women in terms of the persistence of disability after severe civilian trauma, and the differences between men and women in the military in terms of use of care, we felt it important to evaluate whether important gender-related differences in posttraumatic disability affect the lives of military personnel who have been deployed. Furthermore, to inform efforts to minimize disability after deployment-related injury, the types of disabilities, including body system affected and disability severity, must be known. If women and men veterans experience different disability outcomes, advancing knowledge about how to minimize disability for each gender would be contingent on understanding these outcomes and any differences that may apply. The purpose of our study was to define the disability profiles of women compared with men after deployment injury.

Specifically, we sought to answer three questions: (1) Do women service members develop different conditions resulting in long-term disability compared with men service members after injuries sustained during deployment? (2) Do women service members have more or less severe disability after deployment injury compared with men service members? (3) Are men or women more likely to return to duty after combat injury?

\section{Materials and Methods}

Our retrospective study was conducted in accordance with a research protocol approved by the San Antonio Military Medical Center institutional review board.

We queried the Department of Defense Trauma Registry (DoDTR; JBSA Fort Sam Houston, TX, USA) for women service members who were injured while deployed in support of OIF/OND and OEF between October 2001 and July 2011. Inclusion into the DoDTR includes an injury that requires treatment at a midlevel military treatment center. Each subject had to have at least one orthopaedic injury. Orthopaedic injuries were confirmed through the Military Orthopaedic Trauma Registry (JBSA Fort Sam Houston, TX, USA). Because records were not available for Navy personnel and the Marines, only Air Force and Army women service members were included. The women subjects were compared with a previously published cohort of men service members who were likewise entrants into DoDTR secondary to an injury sustained during deployment and who had at least one orthopaedic injury [6].

The Air Force and Army Physical Evaluation Board (PEB) database contained two outcomes of interest. The PEB is a board of military officers and medical personnel who determine if after a period of recovery, an injured service member is recovered enough to continue his or her service on active-duty status. A service member who is being reviewed by the PEB will be evaluated by pertinent medical and psychiatric specialists who make diagnoses according to their individual expertise. The PEB reviews the medical documentation, considers the military regulations describing the standards for retention on active duty, and then determines if the service member is "fit" or "unfit" for duty based on whether he or she continues to meet retention standards. If there are no medical conditions that cause the service member to no longer meet retention standards, he or she is considered "fit" for duty. Those service members who are not fit for duty are medically retired or separated from active-duty status. The PEB must also enumerate the medical conditions that support the "unfit for duty" determination in accordance with the Veterans Affairs Schedule for Rating Disabilities (VASRD) published within the Code of Federal Regulations, Title 38. 
Table 1. Percentage of service members with unfitting conditions

\begin{tabular}{llll}
\hline Condition & Women $(\%)(\mathrm{n}=83)$ & Men $(\%)(\mathrm{n}=378)$ & $\mathrm{p}$ value \\
\hline Arthritis & 58 & 35 & 19 \\
Pain disorder & 1 & 27 & $<0.001$ \\
Nerve injury with resultant loss of function & 27 & 7 & 1 \\
Nerve injury with resultant neurogenic pain & 1 & 10 & $<0.001$ \\
Muscle condition & 7 & 6 & $<0.001$ \\
Upper extremity amputation & 7 & 16 & $<0.001$ \\
Lower extremity amputation & 25 & 14 & $<0.001$ \\
Back pain & 8 & 9 & $<0.001$ \\
Spine/spinal cord injury & 0 & 9 & $<0.001$ \\
Scar & 8 & 27 & 11 \\
Posttraumatic stress disorder & 24 & 11 \\
Traumatic brain injury & 16 & 2 & $<0.001$ \\
Chest condition & 1 & 7 & 17 \\
Abdominal or pelvic condition & 5 & 7 & $<.001$ \\
Condition of ear, eyes, nose, or throat & 1 & 4 & $<0.001$ \\
Head condition & 4 & $<0.001$ \\
\hline
\end{tabular}

The first outcome of interest from the PEB disposition is the list of conditions that preclude the medically retired service member from being retained on active-duty status. These conditions correspond with a persistent medical diagnosis and are considered as "disabling conditions" because they are the physical or medical issues that cause activity limitations or restrictions that hinder the service member's ability to perform his or her active-duty job. The second outcome of interest is the "percent disability" assigned to each disabling condition. The percentage is determined by the PEB per disabling condition and reflects a spectrum of severity by which the condition detracts from the service member's wholeness as a soldier or airman. More severe conditions that result in greater degrees of activity limitation or restriction are assigned higher disability percentages than less severe conditions. The disability percentages for each condition are tallied for an overall percentage disability rating in accordance with the VASRD system.

The disabling conditions for each subject were categorized by body system affected as described by Cross et al. [6]. The conditions per body system were then analyzed as categorical data as a condition being "present" or "not present" for that body system. The unfitting conditions between men and women were then compared using Fisher's exact test. The percent disability ratings were also categorized per body system but as continuous variables. The percent disability ratings between men and women were compared using an unpaired, two-tailed t-test. Returnto-duty proportions were compared between battle-injured men and women using Fisher's exact test. Statistical significance was set at $\mathrm{p}<0.05$.
Our study included 368 women service members, 83 of whom were medically retired because of their injuries and we have PEB data used for this analysis. The median subject age was 26 years (range, 18-55 years), 328 (89\%) were of enlisted ranks, and $40(11 \%)$ were officers. Of the 368 women, $133(36 \%)$ were injured in combat, whereas $235(64 \%)$ were injured in nonbattle-deployed scenarios. The men comprising the control cohort consisted of 378 combat-injured service members derived from a prior cohort of 1333 soldiers, 450 of whom were medically retired as a result of their combat injuries [6]. Three hundred seventy-eight of the 450 men service members medically retired by the PEB had at least one orthopaedic injury, which allowed their inclusion for this study. The men service members had a median age of 24 years (range, 18 54 years), 353 (96\%) were enlisted rank, and 15 (4\%) were officers.

\section{Results}

Women experienced a higher frequency of conditions for arthritis-related disability (58\% [48 of 83] of women versus $35 \%$ [133 of 378] of men, $p=0.002$; relative risk [RR], 1.644; 95\% confidence interval [95\% CI], 1.307-2.067), whereas men experienced higher frequencies of pain-related conditions such as generalized pain (1\% [one of 83] of women versus 19\% [59 of 378] of men, $\mathrm{p}<0.001$; RR, 0.077 ; 95\% CI, 0.011-0.549) and neurogenic pain disorders (1\% [one of 83] of women versus 7\% [27 of 378] of men, $\mathrm{p}=<0.001$; RR, 0.169; 95\% CI, 0.023-1.224). Men also had higher frequencies of spine and spinal cord 
Table 2. Percentage disability rating per unfitting condition $(\% \pm \mathrm{SEM})$

\begin{tabular}{llll}
\hline Condition & Women & Men & \\
\hline Arthritis & $15 \pm 2$ & $18 \pm 1$ & $<$ value \\
Pain disorder & $7 \pm 3$ & $12 \pm 1$ & $<.001$ \\
Nerve injury with resultant loss of function & $35 \pm 5$ & $35 \pm 2$ & $<0.001$ \\
Muscle condition & $30 \pm 5$ & $29 \pm 3$ & $<001$ \\
Upper extremity amputation & $83 \pm 5$ & $75 \pm 2$ & $< \pm 0.001$ \\
Lower extremity amputation & $60 \pm 5$ & $14 \pm 2$ & $<0.001$ \\
Back pain & $17 \pm 3$ & $23 \pm 4$ & $<0.001$ \\
Scar & $20 \pm 6$ & $19 \pm 1$ & $<0.001$ \\
Posttraumatic stress disorder & $38 \pm 6$ & $23 \pm 3$ & $<0.001$ \\
Traumatic brain injury & $25 \pm 4$ & $47 \pm 8$ & $<0.001$ \\
Abdominal or pelvic condition & $33 \pm 10$ & $61 \pm 14$ & $<0.001$ \\
Head condition & $20 \pm 10$ & $<0.001$ \\
\hline
\end{tabular}

conditions ( $0 \%$ women versus $9 \%$ [32 of 378] of men, $\mathrm{p}=<0.001$; RR, 0.069; 95\% CI, 0.004-1.122) and disabilities of the eye, ear, nose, or throat (1\% [one of 83] of women versus 17\% [63 of 378] of men, $\mathrm{p}<0.001$; RR, $0.072 ; 95 \% \mathrm{CI}, 0.010-0.514])$. With the numbers available, there were no differences in posttraumatic stress disorder (PTSD) or other psychiatric disorder frequencies between the genders (Table 1). Women and men service members both had a mean of 1.9 disabling conditions per individual (1.9 \pm 0.88 for women; $1.9 \pm 0.44$ for men).

For all orthopaedic-related unfitting conditions, there were no differences between women and men disability ratings. Women had more severely rated PTSD compared with men $(38 \%$ for women versus $19 \%$ for men (difference, $19 \% \pm 4.6 \%$; 95\% CI, 28-9.8) with ratings double that of their men counterparts. Other nonorthopaedic conditions between the genders were not differently rated (Table 2).

Of the 133 combat-injured women, 64 (48\%) were unable to return to duty. The previously published cohort [6] of men analyzed 1333 combat-injured individuals, 450 of whom $(34 \%)$ were medically retired or separated (unable to return to duty). The return-to-duty proportion is lower for combat-injured females ( $\mathrm{p}=0.003$; RR, 1.425; 95\% CI, 1.177-1.727). For women injured in noncombat circumstances, only $8 \%$ (19 of 238) were unable to return to duty. No male comparison group for noncombat injury was included.

\section{Discussion}

The US military has been engaged in active combat operations for 13 years, resulting in a new generation of war veterans. Maximizing healthcare access and benefits requires we understand what problems these veterans have once they leave the military. The civilian trauma literature supports that there may be differences between the genders when it comes to both physical and mental health outcomes after trauma. We sought to determine if military-designated disability was different between the genders after trauma sustained in a deployed environment. We found that the types of problems men and women service members have are largely not different but that women have more severely rated PTSD compared with men. We also found that after injury sustained in a combat environment, women returned to duty less often compared with men injured in combat.

Our study has a number of limitations. First, the PEB results used as outcome measures are unique to the military and may therefore be difficult to extrapolate to civilian trauma and disability outcomes. The PEB system in the military, however, is analogous to a civilian workers compensation system in that it evaluates whether an injured service member can return to work (return to duty). As such, the PEB result provides a valid interpretation of military job descriptions, the physical nature of these jobs, which extends beyond the physical demands asked of the civilian workforce, and a service member's ability or inability to perform his or her job on active duty because of limitations or restrictions secondary to an injury. The PEB, like any evaluation system, is subject to the biases held by its members. There is no literature to support gender bias in this evaluation process, but such a bias toward or against female service members is possible. However, the PEB is constrained by specific published VASRD guidelines, which instruct the PEB members how disability should be assigned the severity percentage rated based on medical documentation. Additionally, the PEB's determination for "fit" or "unfit" for duty is constrained by the military's published guidelines for military service and retention, which is the same between the genders. There is no way to comment on the degree of subjectivity imposed on the PEB 
outcomes presented in this study; however, the VASRD and military standards for retention guidelines are intended to assure the PEB process is as objective as possible.

Second, the comparison cohort of men is from a previously published work rather than collected in tandem with the cohort of women [6]. The previous cohort of men was used because it has been extensively studied. To date, no other cohort of battle-injured service members is better described from the point of injury to their final PEB dispositions [6]. In understanding the course of injury to medical discharge, this cohort provides an adequate standard by which to examine other subsets of the combat- and noncombat-wounded populations. Third, the retrospective nature of our study is prone to the inherent biases of such design, which for this registry-based study may include missing data and incorrect data entry. Retrospective analysis, however, allows for analysis of the entire war period from 2001 to the present. The DoDTR is an established registry with an excellent track record of informing several clinical practice guidelines and research. The PEB database is likewise a consistent source secondary to its adherence to the VASRD and requirement of physician-diagnosed conditions as a basis for determining disabling conditions. Fourth, the study does not include data on the job descriptions of the subjects included in this comparison. Injury patterns and resultant disability may be affected by military occupational exposures. Given that women were excluded from frontline combat units during the entire period included in this study, the combat exposures experienced by the men in the comparison cohort are presumably different that those experience by the women subjects. This very restriction of women in combat units makes comparing the numerous military job descriptions between the genders difficult and even arbitrary. However, the lack of frontline combat exposure for women makes the findings that women had more severe findings of PTSD even more poignant. Finally, our disability data for both the men and women include only subjects who served in the Army or Air Force, which excludes those who served in the Navy and Marines. The types of deployment exposures are potentially different for the Navy and Marines, which could influence outcomes. This limitation is secondary to the availability of PEB data from the Navy and Marines and results in some loss of external validity for veterans from these services.

The overall disability profiles between genders are not different, including average number of disabling conditions per individuals. That women have a higher frequency of arthritis-related conditions is consistent with prior publications on degenerative arthritis demonstrating sexual dimorphism in the rates of degenerative, or idiopathic, arthritis [11, 16, 24]. The presence or absence of this gender difference is not known for posttraumatic arthritis.
A prior study on arthritis-related disability identified that a disabling arthritic condition after combat injury is the posttraumatic result of a direct joint injury $94 \%$ of the time, whereas $6 \%$ of disabling arthritis conditions are the result of conditions or injuries diagnosed before deployment [30]. As such, the arthritic conditions in our cohort may be presumed to be posttraumatic in nature, potentially establishing a similar gender difference between degenerative and posttrauma arthritis rates. Men in our study had higher frequencies of generalized chronic pain and neurogenic pain conditions, which contradicts previous work that demonstrated higher pain frequencies and healthcare use for pain conditions among women veterans [17-19]. Although this may reflect a true difference in pain condition rates, the discrepancy between our results and previous literature likely points to the evolving nature of disability as service members transition to the care of the VA after separation from the military or that having a disability after injury does not necessarily lead to one seeking care for that disability in the VA. One notable lack of difference is between genders for frequency of abdominal and pelvic conditions. Women veterans are known to have higher frequencies of menstrual and other reproductive disorders compared with their civilian counterparts, a fact one may expect to see reflected in the female disability profile [5, 23]. This is likely the result of the fact that such gynecologic complaints are not linked to specific injuries, whereas disabling conditions are usually from the injury.

The disability ratings between genders were similar for all conditions with the exception of PTSD. Much debate is present in the military and veteran literature about gender differences in PTSD with opinions supporting and opposing the presence of a gender difference [10, 13, 14, 27, 33]. Our results do not support that PTSD is more common in women but results in more substantial disability than experienced by their men counterparts, and the rates identified are consistent with previous reports. This may reflect a gender difference in how the deployed environment and bodily injury are perceived and experienced by women compared with men [29, 31, 32]. Such perceptions are difficult to study; however, a small series on female amputees does support that the woman amputee experiences her limb loss in different ways and has different types of concerns about the loss (including body image, personal safety, etc) compared with the male amputee [3]. Considering the holistic aspect of these severe combat injuries, our result suggests that the severity of PTSD could be attributable to how personally affected the woman service member is by her experience. Other aspects, as suggested in the literature, including how women deal with witnessing death, history of military sex trauma, and concomitant mental health conditions, may exacerbate PTSD symptoms for women service members [20, 22, 34]. 
Our results suggest a marked difference in the return-toduty rates between genders after combat injury. This is counterintuitive in that men service members typically have job descriptions that include direct combat such as in infantry and armored units [2]. During the vast portion of OIF/ OND (2003-2011) and OEF (2001-2014), women were banned from holding direct-combat jobs but instead provided a number of support roles such as military police, transport, logistics, medical care, etc. Returning to the physical demands of an infantry job as opposed to a transport or logistics job would presumably be more difficult. Our results suggest, however, that irrespective of the typical job descriptions held by the two genders, women are less likely to continue service on active duty. This might reflect a desire by more women to leave the military or to not appeal the PEB result to change job descriptions to accommodate continuing on active duty. It may also reflect an inherent, yet undefined, severity of injury, which was also suggested by prior work demonstrating higher case fatality rates after combat injury for women compared with men [7].

In summary, the disability profiles and disability severities of women and men veterans are largely not different. A difference in frequency in arthritis conditions is consistent with the civilian trauma literature, whereas the frequency of pain-related disability is not. Our data suggest that women are more severely affected. In total, the clinical relevance of our findings does support some areas of gender differences after deployment injury, where efforts to minimize disability might be directed. Finally, despite military job descriptions, which have been different between the genders, women are less likely to return to duty after combat injury. Additional study of combat exposure, injury prevention and protection, and postinjury care are warranted to minimize disability for both men and women after deployment. This study suggests gender differences in reaction to deployment and combat, a finding with the implication that minimizing disability may require different approaches between genders.

Acknowledgments We thank the Department of Defense Trauma Registry and the Military Orthopaedic Trauma Registry for providing data for this study.

\section{References}

1. A profile of women veterans today. (2013) Women's Health Services, Department of Veterans Affairs. Available at: www. womenshealth.va.gov/WOMENSHEALTH/docs/ProfileSheet_ 073113_508c.pdf. Accessed April 22, 2014.

2. Belisle JG, Wenke JC, Krueger CA. Return-to-duty-rates among US military combat-related amputees in the global war on terror: job description matters. J Trauma Acute Care Surg. 2013;75:279-286.

3. Carter JK. Traumatic amputation: psychosocial adjustment of six Army women to loss of one of more limbs. J Rehab Research Develop. 2012;49:1443-1456.
4. Centers for Disease Control and Prevention. FastStats all injuries. Available at: www.cdc.gov/nchs/fastats/injury.htm. Accessed September 23, 2014.

5. Cohen BE, Maguen S, Bertenthal D, Shi Y, Jacoby V, Seal KH. Reproductive and other health outcomes in Iraq and Afghanistan women veterans using VA health care: association with mental health diagnoses. Womens Health Issues. 2012;22:461-471.

6. Cross JD, Ficke JR, Hsu JR, Masini BD, Wenke JC. Battlefield orthopaedic injuries cause the majority of long-term disabilities. $J$ Am Acad Orthop Surg. 2011;19(Suppl 1):S1-S7.

7. Cross JD, Johnson AE, Wenke JC, Bosse MJ, Ficke JR. Mortality in female war veterans of Operations Enduring and Iraqi Freedom. Clin Orthop Relat Res. 2011;469:1956-1961.

8. Dimopoulou I, Anthi A, Mastora Z, Theodorakopoulou M, Konstandinidis A, Evangelou E, Mandragos K, Roussos C. Health-related quality of life and disability in survivors of multiple trauma one year after intensive care unit discharge. Am J Phys Med Rehabil. 2004;83:171-176.

9. Fan JK, McLeod CB, Koehoorn M. Sociodemographic, clinical, and work characteristics associated with return-to-work outcomes following surgery for work-related knee injury. Scand $J$ Work Environ Health. 2010;36:332-338.

10. Fear NT, Jones M, Murphy D, Hull L, Iversen AC, Coker B, Machell L, Sundin J, Woodhead C, Jones N, Greenberg N, Landau S, Daneker C, Rona RJ, Hotopf M, Wessely S. What are the consequences of deployment to Iraq and Afghanistan on the mental health of the UK armed forces? A cohort study. Lancet. 2010;375:1728-1797.

11. Felson DT, Naimark A, Anderson J, Kazis L, Castelli W, Meenan RF. The prevalence of knee osteoarthritis in the elderly. The Framingham Osteoarthritis Study. Arthritis Rheum. 1987;30:914918.

12. Fontana A, Rosenheck R, Desai R. Female veterans of Iraq and Afghanistan seeking care from VA specialized PTSD programs: comparison with male veteran sand female war zone veterans of previous eras. J Womens Health. 2010;19:751-757.

13. Gates MA, Holowka DW, Vasterling JJ, Keane TM, Marx BP, Rosen RC. Posttraumatic stress disorder in veterans and military personnel: epidemiology, screening, and care recognition. Psychol Serv. 2012;9:361-382.

14. Grandus JL. Epidemiology of PTSD. National Center for PTSD. Updated January 30,2014. Available at: www.ptsd.va.gov/ professional/PTSD-overview/epidemiological-facts-ptsd.asp. Accessed April 23, 2014.

15. Haider AM, Crompton JG, Oyetunji T, Stevens KA, Efron DT, Kieninger AN, Change DC, Cornwell EE, Haut ER. Females have fewer complications and lower mortality following trauma than similarly injured males: a risk adjusted analysis of adults in the National Trauma Data Bank. Surgery. 2009:146:308-315.

16. Hanna FS, Teichtahl AJ, Wluka AE, Wang Y, Urguhart DM, English DR, Giles GG, Cicuttini FM. Women have increased rates of cartilage loss and progression of cartilage defects at the knee than men: a gender study of adults without clinical knee osteoarthritis. Menopause. 2009;16:666-670.

17. Haskell SG, Brandt CA, Krebs EE, Skanderson M, Kerns RD, Goulet JL. Pain among Veterans of Operations Enduring Freedom and Iraqi Freedom: do women and men differ? Pain Med. 2009;10:1167-1173.

18. Haskell SG, Gordon KS, Mattocks K, Duggal M, Erdos J, Justice A, Brandt CA. Gender differences in rating of depression, PTSD, pain, obesity, and military sexual trauma among Connecticut war veterans of Iraq and Afghanistan. J Womens Health. 2010;19: 267-271.

19. Haskell SG, Ning Y, Krebs E, Goulet J, Mattocks K, Kerns R, Brandt C. Prevalence of painful musculoskeletal conditions in female and male veterans in 7 years after return from deployment 
in Operation Enduring Freedom/Operation Iraqi Freedom. Clin J Pain. 2012;28:163-167.

20. Hassija CM, Jakupcak M, Maguen S, Shipherd JC. The influence of combat and interpersonal trauma on PTSD, depression, and alcohol misuse in US Gulf War and OEF/OIF women veterans. $J$ Trauma Stress. 2012;25:216-219.

21. Hoge CW, Auchterlonie JL, Milliken CS. Mental health problems, use of mental health services, and attrition from military service after returning from deployment to Iraq or Afghanistan. JAMA. 2006;295:1023-1032.

22. Kang H, Dalager N, Mahan C, Ishii E. The role of sexual assault on the risk of PTSD among Gulf War veterans. Ann Epidemiol. 2005; 15:191-195.

23. Kang H, Magee C, Mahan C, Lee K, Murphey F, Jackson L. Pregnancy outcomes among US Gulf War veterans: a population based survey of 30,000 veterans. Ann Epidemiol. 2001;11: 504-511.

24. Kopec JA, Rahman MM, Berthelot JM, Le Petit C, Aghajanian J, Sayre EC, Cibere J, Anis AH, Badley EM. Descriptive epidemiology of osteoarthritis in British Columbia, Canada. $J$ Rheumatol. 2007;34:3863-3893.

25. Medical evacuations from Afghanistan during Operation Enduring Freedom, active and reserve component, US Armed Forces, 7 October 2001-31 December 2012. MSMR. 2013;20:2-8.

26. Medical evacuations from Operation Iraqi Freedom. Operation New Dawn, active and reserve components, US armed forces, 2003-2011. MSMR. 2012;19:18-21.

27. Olff M, Langeland W, Draijer N, Gersons BP. Gender differences in posttraumatic stress disorder. Psychol Bull. 2007;133:183-204.
28. Puolakka K, Ylinen J, Neva M, Kautiainen H, Häkkinen A. Risk factors for back pain-related loss of working time after surgery for lumbar disc herniation: a 5-year follow-up study. Eur Spine J. 2008;17:386-392.

29. Resnick EM, Mallampalli M, Carter CL. Current challenges in female veterans' health. $J$ Womens Health. 2012;21:895-900.

30. Rivera JC, Wenke JC, Buckwalter JA, Ficke JR, Johnson AE. Posttraumatic osteoarthritis caused by battlefield injuries: the primary source of disability in warriors. J Am Acad Orthop Surg. 2012;20(Suppl 1):S64-S69.

31. Starr AJ, Smith WR, Frawley WH, Borer DS, Morgan SJ, Reinert CM, Mendoza-Welch M. Symptoms of posttraumatic stress disorder after orthopaedic trauma. J Bone Joint Surg Am. 2004; 86:1115-1121.

32. Street AE, Vogt D, Dutra L. A new generation of women veterans: stressors faced by women deployed to Iraq and Afghanistan. Clin Psych Rev. 2009;29:685-694.

33. Tolin DF, Foa EB. Sex differences in trauma and posttraumatic stress disorder: a quantitative review of 25 years of research. Psychol Bull. 2006;132:959-992.

34. Wells TS, LeardMann CA, Fortuna SO, Smith B, Smith TC, Ryan MA, Boyko EJ, Blazer D, Millennium Cohort Study Team. A prospective study of depression following combat deployment in support of the wars in Iraq and Afghanistan. Am J Public Health. 2010;100:90-99.

35. Wohltmann CD, Franklin GA, Boaz MSN, Luchette FA, Kearney $\mathrm{MD}$, Richardson D, Spain DA. A multicenter evaluation of whether gender dimorphism affects survival after trauma. Am J Surg. 2001;181:297-300. 